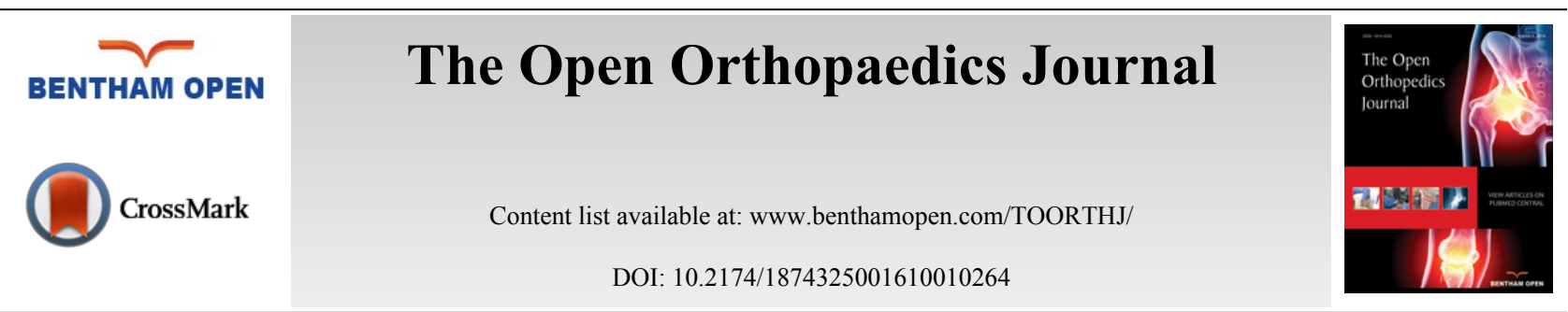

\title{
EDITORIAL
}

\section{Current Treatment Options for Rotator Cuff Tears}

Rotator cuff tears are the most frequent tendon injury in the adult population [1].

Accounting for more than 4.5 million physician visits and 250,000 surgeries per year, rotator cuff injuries are among the most common musculoskeletal injuries in the United States [2,3]. The cost per rotator cuff repair has been estimated as 15,306 US-dollars, resulting in an annual societal burden of almost 4 billion US-dollars in the United States [3]. With the growing number of rotator cuff repairs over the last 20 years, this burden has been continuously increasing [4 - 6] and is expected to further increase in the future.

Given the importance of this topic, this thematic issue of the Open Orthopaedics Journal focusses on "Current Concepts for the Treatment of Rotator Cuff Tears".

The first manuscript by Moulton et al. describes the epidemiology, pathobiomechanics and natural history of rotator cuff tears. The next manuscript by Petri et al. describes the non-surgical treatment options, which still remain the first treatment of choice for the majority of patients. Hawi et al. then put the focus on debriding procedures for rotator cuff tears. Progressing to rotator cuff repair, Spiegl et al. compare the advantages and disadvantages of single-row vs. double-row repairs. This is followed by the detailed description of the surgical technique of a knotless linked doublerow rotator cuff repair by Mook et al. Greenspoon et al. then elucidate the role of platelet-rich plasma and other biological adjuncts to cuff repair, with a particular focus on the available evidence.

Progressing to rotator cuff tears with poor tendon quality and irreparable tears, Petri et al. describe the indications, technique and results of patch-augmented rotator cuff repair and the rather novel technique of Superior Capsule Reconstruction. Of particular importance to the patients outcomes, Kokmeyer et al. present their concept of postoperative rehabilitation after rotator cuff repair. The thematic issue is completed by the manuscripts on tendon transfers (Greenspoon et al.) and reverse total shoulder arthroplasty (Virk et al.) for irreparable rotator cuff tears.

To summarize, the decision-making and treatment algorithms for rotator cuff tears keep evolving. As fostered by significant improvements in surgical instruments and surgical technique, patients outcomes have been improving remarkably in the recent few years. However, there is still a lot of room for improvement to achieve better results for our patients in the future.

\section{REFERENCES}

[1] Safran O, Schroeder J, Bloom R, Weil Y, Milgrom C. Natural history of nonoperatively treated symptomatic rotator cuff tears in patients 60 years old or younger. Am J Sports Med 2011; 39(4): 710-4. [http://dx.doi.org/10.1177/0363546510393944] [PMID: 21310940]

[2] Oh LS, Wolf BR, Hall MP, Levy BA, Marx RG. Indications for rotator cuff repair: a systematic review. Clin Orthop Relat Res 2007; 455(455): 52-63. [http://dx.doi.org/10.1097/BLO.0b013e31802fc175] [PMID: 17179786]

[3] Mather RC III, Koenig L, Acevedo D, et al. The societal and economic value of rotator cuff repair. J Bone Joint Surg Am 2013; 95(22): 1993-2000.

[http://dx.doi.org/10.2106/JBJS.L.01495] [PMID: 24257656]

[4] Iyengar JJ, Samagh SP, Schairer W, Singh G, Valone FH 3rd, Feeley BT. Current trends in rotator cuff repair: surgical technique, setting, and cost. Arthroscopy 2014; 30(3): 284-8. [http://dx.doi.org/10.1016/j.arthro.2013.11.018] 
[5] Ensor KL, Kwon YW, Dibeneditto MR, Zuckerman JD, Rokito AS. The rising incidence of rotator cuff repairs. J Shoulder Elbow Surg 2013; 22(12): 1628-32.

[http://dx.doi.org/10.1016/j.jse.2013.01.006] [PMID: 23466172]

[6] Colvin AC, Egorova N, Harrison AK, Moskowitz A, Flatow EL. National trends in rotator cuff repair. J Bone Joint Surg Am 2012; 94(3): $227-33$

[http://dx.doi.org/10.2106/JBJS.J.00739] [PMID: 22298054]

Maximilian Petri

Trauma Department Hannover Medical School Carl-Neuberg-Str. 1, 30625 Hannover

Germany

Email: petri.maximilian@mh-hannover.de

(C) Maximilian Petri; Licensee Bentham Open.

This is an open access article licensed under the terms of the Creative Commons Attribution-Non-Commercial 4.0 International Public License (CC BY-NC 4.0) (https://creativecommons.org/licenses/by-nc/4.0/legalcode), which permits unrestricted, non-commercial use, distribution and reproduction in any medium, provided the work is properly cited. 